\title{
Estudo das tematizações de estabelecimentos gastronômicos do Distrito Federal
}

\author{
Study of thematizations of gastronomic establishments of the Distrito Federal
}

Estudio de tematizaciones de establecimientos gastronómicos del Distrito Federal.

\section{Bianca Meneguci Barcelos ${ }^{1}$}

Resumo: Este artigo analisa os estabelecimentos gastronômicos do Distrito Federal passando pelas suas quatro categorias temáticas: a temática relicária, onde os ambientes agregam relíquias históricas; a temática paródica, onde o uso de artefatos e dispositivos decorativos nestes espaços são simulações e releituras; a temática reflexiva, que em seus locais, o tema é a marca e a marca é o tema; e a temática étnica que apresenta em seus estabelecimentos uma gastronomia voltada para a cultura de um determinado país. A análise foi feita dentro dos estabelecimentos gastronômicos temáticos: Dólar Furado, Mumbai Restaurante, Urso Beer e Victrola Gastrobar a partir do olhar dos consumidores, gerentes e proprietários desses espaços. E, teve como foco obter respostas a respeito do público consumidor e seu grau de aceitação nesses ambientes, além de observar os proprietários e gerentes lidarem com o mercado competitivo buscando propor experiências singulares dentro da proposta de seus estabelecimentos. Como resultado, foi observado que os estabelecimentos visitados conseguem transmitir suas propostas a partir de seus elementos temáticos, além de proporcionarem de formas criativas o entretenimento para o seu público. E, no ponto de vista dos clientes, eles interpretam os elementos temáticos e abraçam as experiências propostas.

Palavras-chave: Ambientes gastronômicos; bares e restaurantes temáticos; eatertainment.

Resumen: Este artículo analiza los establecimientos gastronómicos del Distrito Federal a través de sus cuatro categorías temáticas: el tema del relicario, donde los ambientes agregan reliquias históricas; el tema paródico, donde el uso de artefactos y dispositivos decorativos en estos espacios son simulaciones y relectos; el tema reflexivo, que en su lugar, el tema es la marca y la marca es el tema; y el tema étnico que presenta en sus establecimientos una cocina centrada en la cultura de un país en particular. El análisis se realizó en establecimientos gastronómicos temáticos: Dólar Furado, Mumbai Restaurante, Urso Beer y Victrola Gastrobar desde los ojos de los consumidores, gerentes y propietarios de estos espacios. Y se centró en obtener respuestas sobre el público consumidor y su grado de aceptación en estos entornos, además de ver a los propietarios y gerentes lidiar con el mercado competitivo tratando de proponer experiencias únicas dentro de la propuesta de sus establecimientos. Como resultado, se observó que los establecimientos visitados pueden transmitir sus propuestas en función de sus elementos temáticos, así como proporcionar entretenimiento a su audiencia de manera creativa. Y desde el punto de vista del cliente, interpretan los elementos temáticos y adoptan las experiencias propuestas.

Palabras clave: Ambientes gastronómicos; bares y restaurantes temáticos; eatertainment.

Abstract: This article analyzes the gastronomic establishments of the Federal District through its four thematic categories: the reliquary theme, where the environments add historical relics; the parodic theme, where the use of artifacts and decorative devices in these spaces are simulations and rereading; the reflective theme, which in its places, the theme is the brand and the brand is the theme; and the ethnic theme that features in its establishments a cuisine focused on the culture of a particular country. The analysis was made within thematic gastronomic establishments: Dólar Furado, Mumbai Restaurante, Urso Beer and Victrola Gastrobar from the eyes of consumers, managers and owners of these spaces. And, it focused on getting answers about the consumer public and its degree of acceptance in these environments, besides watching the owners and managers deal with the competitive market trying to propose unique experiences within the proposal of their establishments. As a result, it was observed that the visited establishments are able to convey their proposals based

1 Estudante de Turismo - Universidade de Brasília. E-mail: biancameneguci@gmail.com Orcid: https://orcid.org/0000-0002-6746-9351 
on their thematic elements, as well as providing entertainment to their audience in creative ways. And from the customer's point of view, they interpret the thematic elements and embrace the proposed experiences.

Keywords: Gastronomic environments; themed bars and restaurants; eatertainment.

\section{Introdução}

Em 1656 na Cidade Livre, hoje Núcleo Bandeirante, o italiano Victor Pelechia ergueu o considerado "primeiro restaurante do Distrito Federal", segundo Silva (1985). Pouco sabese sobre este restaurante, mas pelo fato de ter sido um estabelecimento gastronômico fundado por um italiano, há chances de Pelechia ter envolvido decoração, música, gastronomia e outros elementos da cultura italiana, criando uma atmosfera temática. Portanto, seu estabelecimento poderia ter sido também o "primeiro restaurante temático do Distrito Federal". Beardsworth e Bryman (1999) definem os estabelecimentos temáticos como:

Por um restaurante temático queremos dizer um estabelecimento de alimentação que veste-se em um complexo de sinais distintos que são em grande parte alheios à atividade de se alimentar. tal complexo pode ser justificadamente denominado "tema" se for constituído de uma ampla gama de narrativas prontamente reconhecíveis extraídas da cultura popular. (BEARDSWORTH e BRYMAN, 1999, p. 228, tradução nossa).

Beardsworth e Bryman (1999) também desenvolveram quatro categorias para os ambientes temáticos gastronômicos, chamando de "classificação de estratégias temáticas", pois mais de uma dessas estratégias poderiam estar presentes em qualquer estabelecimento. Segundo os autores, a variedade de restaurantes e bares temáticos que existem na sociedade contemporânea é aparente. Contudo, foi possível identificar certos padrões recorrentes nesses espaços, que poderiam ser elaborados para formar uma classificação viável de dispositivos de temas. A categorização a seguir representa uma tentativa inicial de trazer alguma ordem para a cena temática. Essas categorias são:

\begin{tabular}{|l|l|}
\hline \multirow{3}{*}{ RELICÁRIA } & \begin{tabular}{l} 
A ênfase é colocada sobre a criação de um \\
ambiente divertido e atraente através da exibição \\
de artefatos preciosos de proveniência conhecida. \\
Esses artefatos são, na verdade, "relíquias" e sua \\
origem os liga diretamente a figuras reverenciadas \\
ou heroicas ou a eventos ou processos altamente \\
salientes no domínio público. A presença de \\
relíquias sagradas introduz um sentido de \\
peregrinação à experiência; a lógica da presença \\
do freguês é tanto homenagear os objetos quanto \\
consumir a comida oferecida. (p.240, tradução \\
nossa). \\
\hline O ambiente é criado principalmente através do uso \\
de artefatos e dispositivos decorativos que são \\
explicitamente falsos. O objetivo do dispositivo de \\
paródia é criar um ambiente mágico baseado em
\end{tabular} \\
\hline
\end{tabular}




\begin{tabular}{|l|l|}
\hline PARÓDICA & $\begin{array}{l}\text { um motivo forte. Tais motivos tendem a enfatizar o } \\
\text { exótico são geralmente construídos a partir de } \\
\text { versões estereotipadas de diversas realidades. } \\
\text { (p.241, tradução nossa). }\end{array}$ \\
\hline REFLEXIVA & $\begin{array}{l}\text { Em certo sentido, o tema é a marca e a marca é o } \\
\text { tema. Em contraste com os dispositivos temáticos } \\
\text { discutidos acima, onde os recursos culturais } \\
\text { externos são apropriados e adaptados, neste caso, } \\
\text { o princípio do tema é gerado internamente e depois } \\
\text { reproduzido infinitamente. (p.243, tradução nossa). }\end{array}$ \\
\hline ÉTNICA & $\begin{array}{l}\text { Como um dispositivo de tematização, isso implica o } \\
\text { uso de arte étnica, decoração, música, fachada } \\
\text { externa, nome e vários sinais estereotipados para } \\
\text { criar um cenário distinto que reivindica ser um } \\
\text { reflexo de alguma cultura exótica, mas } \\
\text { reconhecível. Estes elementos temáticos existem } \\
\text { ao lado da provisão de uma culinária etnicamente } \\
\text { marcada. Os marcadores étnicos refletem } \\
\text { associações construídas de longa data entre } \\
\text { alimentos, lugares e pessoas. No entanto, cozinhas } \\
\text { etnicamente marcadas tendem a ser adaptadas aos } \\
\text { recursos culinários e convenções da cultura } \\
\text { hospedeira. Isso novamente levanta questões sobre } \\
\text { a "autenticidade" dos pratos oferecidos e até onde } \\
\text { os clientes estão em busca de uma experiência } \\
\text { gustativa "autêntica". (p.242, tradução nossa). }\end{array}$ \\
\hline
\end{tabular}

A partir dessas informações, o presente artigo tem como objetivo analisar o ponto de vista dos consumidores, proprietários e gerentes de estabelecimentos gastronômicos do DF que se encaixam dentro dessas categorias temáticas e a promoção do "eatertainment", Gottdiener (1997) unindo nesses espaços o ato de se alimentar com o divertimento.

No Distrito Federal há uma vasta oferta gastronômica e os estabelecimentos são submetidos à inovação e a criatividade para sobreviverem no mercado competitivo, buscando promover experiências ímpares em suas propostas. De certo modo, isso otimiza o turismo dos próprios moradores locais, os chamados "turistas cidadãos" e também é um incentivo para o desenvolvimento de futuros roteiros gastronômicos e novas programações de lazer no Distrito Federal.

[...] trata-se, assim, do conceito de turista cidadão, o habitante que desenvolve um relacionamento diferenciado com o local onde mora no seu tempo de lazer, quebrando o modelo existencial da sociedade industrial criticado por Jost Krippendorf (trabalho - moradia - lazer - viagem), de acordo com o qual o lazer, as práticas sociais capazes de restabelecer o equilíbrio físico e emocional do homem contemporâneo, só seria possível em lugares distantes da própria residência. (SALES, 2006, p.117)

\section{Metodologia}

A pesquisa de cunho qualitativo observa os fenômenos ao redor dos estabelecimentos temáticos do Distrito Federal. Para chegar aos resultados foram 
realizadas entrevistas semi-estruturadas aplicadas entre os dias 11 a 21 de Julho de 2019, nos seguintes estabelecimentos: Dólar Furado, Mumbai Restaurante, Urso Beer e Victrola Gastrobar. Também foi feita uma revisão sistemática de textos sobre o assunto, por meio de fichamentos executados quinzenalmente e apresentados para a orientação a fim de discutir sobre o conteúdo tratado em cada leitura. O textos foram buscados no primeiro semestre de 2018 na Biblioteca Central da UnB (BCE) e no Google Acadêmico. Inicialmente, o termo buscado foi "restaurante temático" e com a carência de textos existentes sobre esse assunto na língua portuguesa, foi pesquisado em língua inglesa "themed restaurants" onde o resultado foi satisfatório.

Quando encontrado o texto do Beradsworth e Bryman (1999) chamado "Late modernity and the dynamics of quasification: the case of the themed restaurant", os autores classificam os estalecimentos em quatro categorias de temas e analisam cada temática criada a partir de suas percepções. Este texto impulsinou encontrar outras publicações a respeito do assunto quando buscado no referencial teórico deste mesmo. Além do Beardsworth e Bryman, também foi lido o livro do Gottdiener (1997) chamado "The theming of America: dreams, media fantasies, and themed environments" onde o autor cria o termo "eatertainment" (eat + entertainment) juntando o ato de se alimentar com o divertimento dando exemplos de lugares como a Disney, McDonald's, Burger King, Hard Rock Café que são lugares vistos como temáticos que trazem alguma experiência lúdica para seus consumidores, não apenas dentro do espaço, mas pelo merchandising e pelas mídias.

Foi lido também "The Role of Authenticity in Ethnic Theme Restaurants", uma publicação de Ebster e Guist (2004) onde os autores focam nos estabelecimentos temáticos étnicos discutindo sobre a autenticidade e apresentando os dois tipos de clientes: o ingênuo e o experiente. Ainda a respeito dos temáticos étnicos, Wood e Muñoz (2006) apresentam em seu artigo "No rules, Just right' oris it? The roled of themed restaurants as cultural embassadors" a expressão "embaixadores culturais" referindo-se ao papel que os restaurantes étnicos fora do país de origem podem exercer quando apresentam uma gastronomia "exótica". E por fim, foi encontrado no livro de Silva (1985) chamado "História de Brasilia" as primeiras coisas que foram estabelecidas no Distrito Federal antes mesmo da atual capital federal ser concebida. Ernesto Silva escreve portanto, sobre o primeiro restaurante de Brasília.

\section{Resultados}

Como já mencionado na metodologia, foram feitas entrevistas com clientes, proprietários e gerentes de estabelecimentos gastronômicos temáticos no DF visando 
analisar as percepções tanto do profissional quanto do consumidor, junto ao olhar da pesquisadora e dos teóricos lidos para chegar aos seguintes resultados:

\section{O relicário}

Dentro da temática relicária foi possível realizar a pesquisa no Victrola Gastrobar. $\mathrm{O}$ Victrola é um bar relicário musical, onde há coleções de discos de vinis, no qual o estabelecimento usa como diferencial e como elemento identitário. Ou seja, apenas discos são tocados no local por meio de uma vitrola e esses discos que são as relíquias, pois são artefatos originais e exclusivos que tornam atrativo e singular o estabelecimento. Os discos de vinis do Victrola são heranças do "Café com Vinil", que funcionava como uma cafeteria e bistrô, antes do atual proprietário comprar e reformar completamente o espaço. Inaugurado em 2014, hoje o Victrola possui um acervo de mais de 4.000 discos contendo clássicos dos mais variados estilos. Neste ambiente, os entrevistados foram: uma cliente, mulher de 31 anos e o proprietário do Victrola.

Conheci o Victrola de forma inesperada. Eu e meu namorado queríamos ir para algum bar, mas não sabíamos qual, então começamos a rodar pelas quadras da Asa Norte e vimos um neon vermelho escrito "Victrola". Eu achei lindo e falei: "Vamos parar aqui" aí paramos e conhecemos. (Feminino, 31 anos)

Para Beardsworth e Bryman (1999) o apelo visual é comum em estabelecimentos temáticos, portanto o fato do letreiro do Victrola ser chamativo é totalmente proposital e coerente com a com a temática do ambiente:

A narrativa é visível e tangível na estrutura física do interior do restaurante e, muitas vezes, no exterior. Esse processo de dar a narrativa uma presença física para o consumidor envolve o uso de uma variedade de dispositivos, incluindo artefatos físicos, som, decoração, logotipos, terminologia de menu, uniformes e mercadorias. (BEARDSWORTH e BRYMAN, 1999, p. 236, tradução nossa)

Quando perguntado sobre o diferencial do Victrola, o proprietário comentou que o tema exclusivo de vinil é bem diferente. Para a cliente, a mesma pergunta foi feita, e ela respondeu: "o diferencial é o vinil, não conheço outro lugar em Brasília que toque discos em todos os dias de funcionamento, e eu amo vinil, o som é diferente, é nostálgico e vintage". Nota-se, portanto que o diferencial dos temáticos relicários são as próprias relíquias, umas vez que elas caracterizam e direcionam a proposta do estabelecimento.

Gottdiener (1997) criou o termo "eatertainment", analisando que havia estabelecimentos que estavam juntando o ato de se alimentar com o divertimento, com o lúdico, mas a iniciativa pode surguir do próprio cliente também, segundo o proprietário do 
Victrola "o cliente que nos proucura para poder atuar como "DJ por um dia". Ou seja, o cliente observa a variedade de vinis expostos, uma vitrola dispinível e isso o estimula para uma experimentação naquele local que vai além do consumo, permitindo-o montar a playlist daquela noite de acordo com os seus gostos musicais.

Em relação à temática, tanto o proprietário como a cliente consideram o Victrola como um estabelecimento temático: "Sim, considero o Victrola temático pelo vinil e com uma tendência pro Rock n roll." (Proprietário do Victrola). "Sim, considero temático. O cardápio é personalizado em forma de vinil e a decoração faz referência à bandas, então na minha percepção é um bar musical, essa é a temática". (Feminino, 31 anos). Portanto, nota-se que para o proprietário, o tema é manifestado pelo vinil (as relíquias) e para a cliente, o tema mostra-se a partir de elementos visuais como o design do cardápio e a decoração.

Imagem 1: Decoração Victrola Gastrobar

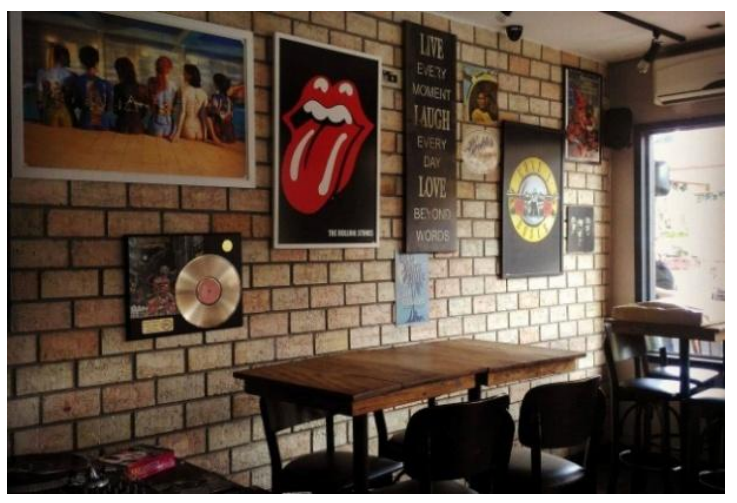

Fonte: www.facebook.com/pg/victrolabrasilia
Imagem 2: Coleção de vinis do Victrola

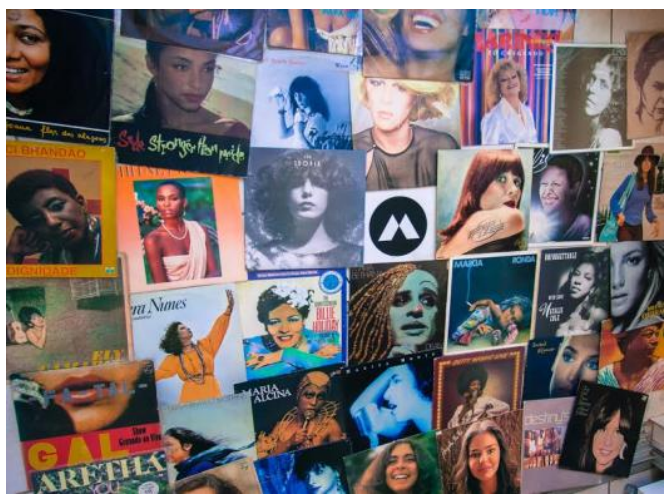

Fonte: www.metropoles.com

\section{O paródico}

Dentro da temática paródica foi possível realizar a pesquisa no Dólar Furado. O Dólar Furado é uma hamburgueira temática como elementos de filmes e desenhos da Disney, Marvel e da Universal Studios. O cenário do Dólar Furado, é composto de uma decoração coerente a respeito das animações, o ambiente é inteiramente decorado e possui 3 cenários: a área externa que contém uma decoração com folhagens sintéticas que remetem a uma floresta, com estátuas grandes de personagens do filme Madagascar, a recepção é uma caverna por onde as pessoas passam e veem vitrines com bonecos da Disney expostos, e, no espaço interno, a decoração remete a casa do Mickey Mouse e contém prateleiras com bonecos e pelúcias de personagens. Neste ambiente, os entrevistados foram: uma cliente, criança de 10 anos e a gerente do Dólar Furado. 


\begin{abstract}
A Hamburgueria ganhou este nome porque o pai da proprietária frequentava uma lanchonete em São Paulo chamada Dólar Furado, além dele gostar muito do filme também. Portanto, ela quis fazer homenagem ao pai. Ela também tem uma irmã que é arquitetura e que projetou tudo isso aqui. Elas já tinham uma ideia do que queriam fazer, mas viajaram para Disney para buscarem inspirações. A caverna por exemplo, é inspirada em um restaurante dentro do parque Island of Adventure - Universal Studios. (Gerente do Dólar Furado)
\end{abstract}

Quando perguntado sobre o diferencial do estabalecimento, a gererente respondeu que o Dólar Furado é diferente porque "se você notar, a maioria das hamburguerias são parecidas. Aqui não, a parte temática é bem trabalhada, indo para o mundo da fantasia. Nossa proposta é mais voltada para o público infantil, mas temos um lado nosso que quer ser criança outra vez, então a hamburgueria encanta os adultos também". A mesma pergunta foi feita para a cliente de 10 anos de idade, que respondeu: "Eu nunca vi outra hamburgueria assim, é muito diferente. É um lugar legal para as pessoas irem porque têm personagens, os hambúrgueres são coloridos, bem diferentes dos outros hambúrgueres que eu já comi”.

Além da cenário temático, a proposta gastronômica do Dólar Furado é brincar com as cores dos pães de hambúrgueres e ter em seu cardápio itens com nomes de personagens. "O pão ganha essa coloração pois são feitos de beterraba, tomate, espinafre e tinta de lula" (gerente do dolar furado). "Eu escolhi o hambúrguer do Pikachu com o milkshake das Meninas Super Poderosas, pois eu li no cardápio e pensei que poderia ser gostoso e é muito gostoso. E eu também gosto desses personagens e gostei muito do pães coloridos, achei bem diferente". (Feminino, 10 anos).

Em relação à temática, a gerente considera o estabelecimento temático "porque nossos itens levam nome de personagens", e para a cliente entevistada é temático "porque é um lugar que tem vários personagens, os hambúrgueres tem nome de personagens, você se sente em um conto de fadas". É interessante analisar que, talvez, para um público adulto, só o fato do cardápio nomear seus itens relacionando com uma proposta específica, isso já é considerado temático, mas para uma criança, talvez ela precise sentir mais do que isso para entar na atmosfera, como observar uma decoração e interagir com personagens.

Quando lidamos com objetos que são significantes de certos conceitos, significados culturais ou ideologias, podemos considerá-los não apenas como "sinais", mas como veículos de signos. Objetos de significação trazem consigo significados. Eles podem ser propositalmente construídos para transmitir significado. A Disneylândia, como parque temático, é um veículo de sinalização da ideologia da Disney. (GOTTDIENER, 1997, p.9, tradução nossa) 
A marca "Disney" possui uma identidade tão forte, que vai além de seus parques temáticos. O Dólar Furado consegue utilizar dos objetos de significação (da Disneylândia) e seus clientes conseguem entender o significado desses elementos. "Eu não escolhi o Dólar Furado, porque eu não conhecia, minha irmã que escolheu. Ela quis me levar para um lugar muito legal para eu comemorar meu aniversário e aqui eu me senti na Disney" (Feminino, 10 anos).

Foi mais legal do que eu imaginei. Eu imaginei que seria uma hamburgueria só com a decoração da Disney e minha irmã disse que o Tigrão (personagem do Ursinho Pooh) ia estar aqui, então eu pensei que so estaria o Tigrão, mas não, todos os funcionários estão fantasiados de personagens. E como é meu aniversário, eles me deram esse bolo de algodão doce, desligaram as luzes e todos os personagens cantaram parabéns para mim, eu me senti especial. (Feminino, 10 anos)

Imagem 3: Espaço interno do Dólar Furado

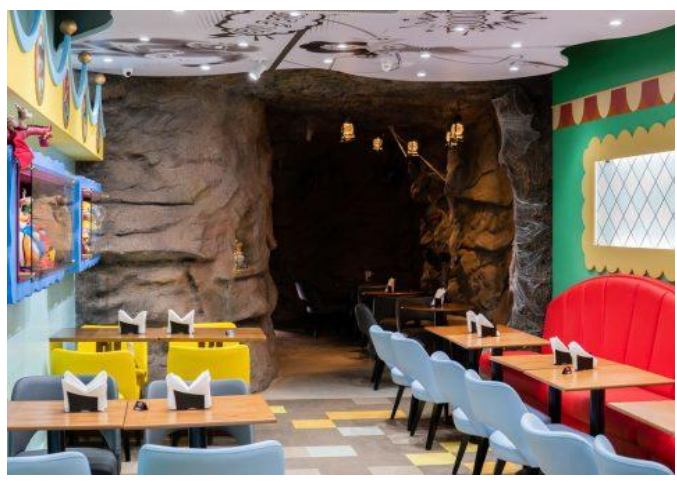

Fonte: www.gulacerta.com.br
Imagem 4: Hambúrguer do Pikachu

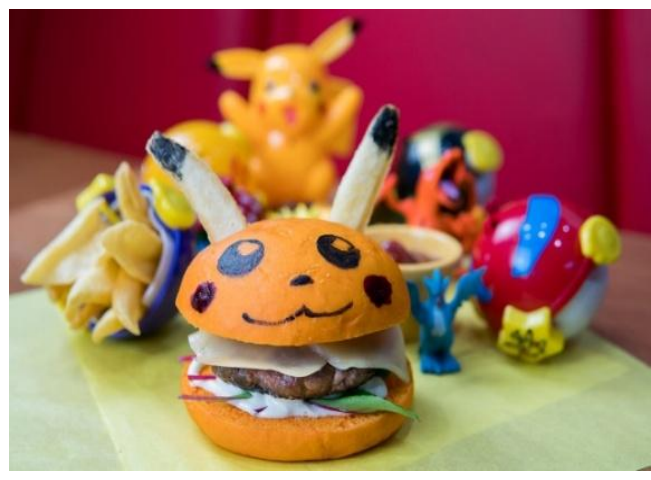

Fonte: www.metropoles.com

\section{O reflexivo}

Dentro da temática reflexiva foi possível realizar a pesquisa no Urso Beer. O Urso Beer é um bar especializado na Cerveja Colorado inspirado no "Bar do Urso", bar oficial da Cerveja Colorado localizado na cidade de São Paulo. Apesar do Urso Beer ser aberto, é no espaço interno que concentra os elementos decorativos. O Bar é revertido por folhagens sintéticas que remetem à floresta, habitat do urso. Além de abranger torneiras de chopps e freezers com a logomarca da Colorado. Neste ambiente, os entrevistados foram: um cliente, homem de 26 anos e o gerente do Urso Beer.

O Urso Beer é um lugar bem colorido e iluminado, as cores chamam. O ambiente parace uma selva pois lembra mesmo um ambiente de um animal selvagem, como o urso. Então eu acho que eles possuem uma decoração que condiz sim com a proposta de promover a Cerveja Colorado. (Masculino, 26 anos). 
Durante a entrevista com o gerente do Urso Beer, ele contou que o carro-chefe da casa "é o proprio chopp da Colorado, são vários tipos de chopps e temos também chopps exclusivos da marca, por ser uma casa exclusiva". O que converge com a fala do cliente entrevistado: "Eu gostei muito do chopp "Colorado Appia" que minha amiga me apresentou, ele é de mel. Gostei muito do chopp e eu nem sou muito de chopp". Portanto, observa-se que em estabelecimentos tematicos reflexivos, a análise "o tema é a marca e a marca é o tema" de Beardsworth e Bryman (1999) é verídica na prática, pois as pessoas frequentam esses espaços com o intuito de consumir produtos da marca.

Eu gostei do bar porque ele é bem concentrado na Cerveja Colorado, ele se especializou nisso (na cerveja), em uma decoração centrada no urso, em um ambiente com aspecto selvagem e confortável. E, quem gosta da Colorado sabe que vai beber essa cerveja aqui, diferente de outros bares que vendem outros rótulos de cervejas. (Masculino, 26 anos).

Segundo Gottdiener (1997, p.79) "franquias famosas como McDonald's, KFC e Burger King estilizam e abstraem seus logotipos identificadores em temas igualmente penetrantes que adicionam ao conjunto de signos e símbolos dentro do ambiente construído". E este efeito é notado na fala do cliente entrevistado do Urso Beer: "o bar é temático demais. Colocaram um jogo de palavras no nome "Urso Beer" pois o que representa o urso? Colorado. O urso é o representante da Cerveja Colorado e o foco é no público que gosta dela". Portanto o Urso Beer consegue fazer com que os clientes indetifiquem que o bar é destinado para apreciadores da Cerveja Colorado, pois a simbologia da marca já é reconhecida. E também, no Urso Beer, é possível comprar produtos da Colorado que ficam expostos como: camisetas, growlers e cervejas da marca.

A comercialização de um restaurante como ambiente temático também desdobra aspectos de merchandising para atrair clientes. Parte da economia dessas cadeias envolve a venda de mercadorias como chapéus, jaquetas e camisetas, onde as lojas Planet Hollywood e Hard Rock Café costumam localizar na entrada do restaurante. Calcula-se que as cadeias mais bem-sucedidas obtêm aproximadamente $25 \%$ de seu lucro com as vendas de roupas e outras mercadorias, além da comida. (GOTTDIENER, 1997, p. 80-81, tradução nossa) 


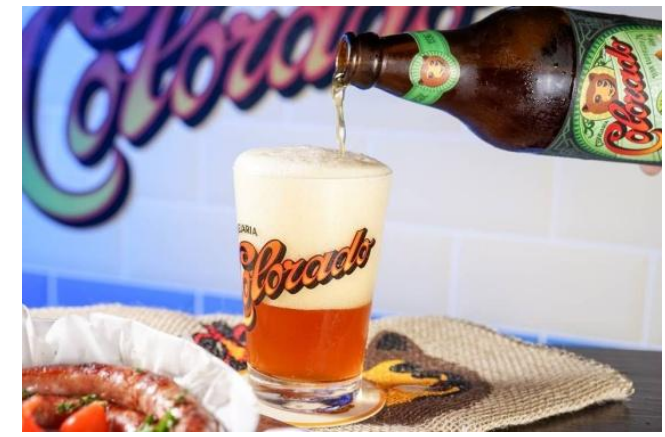

Fonte: www.metropoles.com

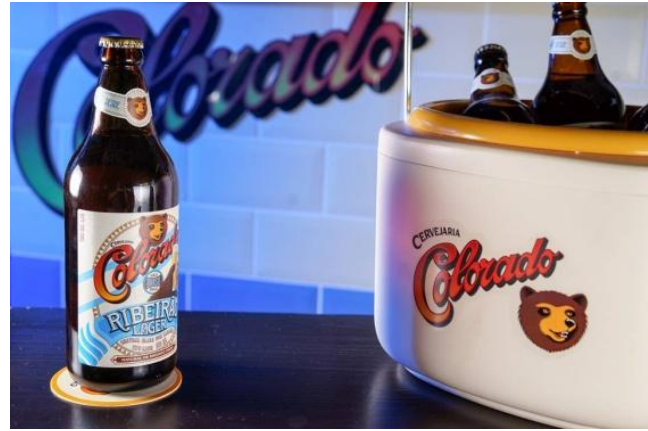

Fonte: www.metropoles.com

\section{0 étnico}

Dentro da temática étnica foi possível realizar a pesquisa no Mumbai Restaurante. Mumbai é um restaurante indiano inaugurado em 2018 e funciona no horário de almoço e no horário de jantar. Neste ambiente, os entrevistados foram: um cliente, homem de 35 anos e a proprietária do Mumbai.

Eu morei fora do Brasil por muito tempo, fui casada com um paquistanês e me divorciei dele há nove anos. Ele sempre vem ao Brasil e dois anos atrás ele visitou aqui e surgiu essa ideia de abri um restaurante. Como ele é paquistanês e mora no Japão, ele tem mais acesso a culinária indiana, porque a Índia e o Paquistão são bem similares, então ele queria que fosse indiana (a culinária). Portanto, nós começamos a obra ano passado, em março. Ele, na verdade é o sócio investidor, eu é que coloquei a mão na massa e fiz tudo. $O$ nome Mumbai saiu da minha cabeça, não tem uma explicação muito coerente, mas eu gosto de pronunciar esse nome, eu acho que ele é autêntico, forte, então não sei da onde eu tirei porque eu não pesquisei nada sobre a Índia. (Proprietária do Mumbai)

Wood e Muñoz (2006) chamam os restaurantes étnicos de "embaixadores culturais", pois a gastronomia consegue apresentar a cultura do país retratado no tema e pode despertar em seus clientes a vontade de viajar e conhecer de fato a localidade. A proprietária do Mumbai acredita que: "a maioria dos meus clientes entendem a proposta, porque são pessoas que já viajaram, que conhecem, que já comeram na Europa ou na própria Índia, mas eu quero trazer as pessoas que não conhecem também”. E quando perguntado ao cliente se ele já tinha visitado a Índia, ele respondeu: "Não, mas tenho amigos indianos e descendentes que conheci na Europa, eles já vieram para cá (Brasil) e estou pretendendo ir para lá (Índia) agora". Portanto, o fato do cliente degustar da culinária indiana, indica que ele está disposto a conhecer um pouco da Índia antes de realizar a sua viagem.

Quando eu aluguel o espaço do Mumbai, eu queria que ele fosse exatamente como ele é, portanto eu contratei uma arquiteta que me ajudou muito, que compreendeu a minha ideia e projetou. Eu queria que tivesse papel de parede, que tivesse o bar, que o telhado fosse preto e que tivesse sofás confortáveis para os clientes. Quando contratei minha arquiteta, eu falei para ela: "eu quero que o Mumbai 
seja um lugar onde você entre e não se sinta em Brasília, que você tenha uma sensação de outro lugar", e eu acho que a gente transmite isso. A ideia dos lustres foram dela (da arquiteta), porque de início a gente ia colocar o mezanino até o final. E aí com as nossas reuniões, achamos mais conveniente ter o pé duplo e ficou muito bom na verdade. Os lustres ela que desenhou e nosso serralheiro projetou. Eu contratei um senhor que trabalha na Torre de TV e ele que fez os lustres. Essas cordas não são de Brasília, elas vieram de fora. (Proprietária do Mumbai)

Ebster e Guist (2004) discutem sobre a autenticidade dentro de estabelecimentos gastronômicos étnicos a partir de seus elementos:

A noção de autenticidade também poderia ser estendida ao interior e exterior do restaurante. Por exemplo, em um restaurante com tema grego, móveis gregos originais e obras de arte modernas produzidas na Grécia podem ser consideradas mais autênticas do que móveis de estilo grego produzidos nos Estados Unidos e réplicas de estátuas gregas antiga. (p. 43)

Analisando o Mumbai Restaurante nesse aspecto, ele parece não ser tão autêntico em sua decoração, por não possuir mobílias indianas. Mas, na questão gastronômica "a comida pode ser considerada autêntica quando preparada por nativos de acordo com a tradição" (LU e FINE apud EBSTER e GUIST, 2004, p.43, tradução nossa) e a proprietária do Mumbai disse na entrevista: "quando estávamos terminando a obra, meu sócio veio do Japão e trouxe nosso Chef indiano. Nosso Chef é do oeste da Índia, por isso a nossa gastronomia é mais voltada para essa região." Portanto no quesito gastronômico, o Mumbai pode ser considerado autêntico. Ainda em relação a autenticidade gastronômica, a proprietaria do Mumbai disse que:

Com certeza o restaurante carrega uma gastronômia autêntica e legítima. Em relação a adaptação, a gente teve que colocar pratos e talheres, mas na verdade, na Índia, eles comem com a mão, e a gente percebe que há pessoas que tem meio que nojinho de comer assim, então tivemos que colocar os pratos e talheres para não espantar tanto. Temos nosso pão que se come com a mão, por isso temos o álcool em gel em cima de todas as mesas, mas tem gente que não tolera pegar comida assim, aí deixamos os pratos e talheres para isso.

Segundo o cliente entrevistado: "A culinária indiana é bem diferenciada, picante, e me agrada exatamente isso, o diferente, o cultural. É claro que tem muita coisa na Índia que não dá para encarar por questões de higiene, mas não anula a cultura deles que eu acho interessante, desde que seja em lugar como este aqui, agradável, limpo e bonito". Portanto, analisando essa fala, é possível notar que o cliente está aberto para as experiências propostas pelo Mumbai, pois considera um lugar higiênico e seguro de se comer e sente-se confortável para conhecer um pouco dos hábitos indianos. Aprofundando nos aspectos de adaptação, a proprietária do Mumbai contou que:

Nós tiramos a pimenta porque a comida indiana é bastante apimentada e isso assusta muito. Então nós deixamos pimentas em 
potinhos em cima das mesas. Se você chegar aqui e falar: "eu quero comer apimentado" o nosso Chef vai colocar pimenta. Mas se você não pedir, como nossas especiarias são picantes, porque não tem como não ser, você já vai sentir uma leve picância na comida, mas nada de "Meu Deus, eu não consigo comer" você vai conseguir comer sim, então eu acho que já está bom demais porque assusta bastante quem não gosta de pimenta.

Ebster e Guist (2004) observam que, clientes que nunca estiveram no país retratado no restaurante podem dar maior importância à autenticidade de um restaurante temático, pois poderiam constituir um substituto parcial para "a coisa real" para eles. No entanto, os clientes culturalmente experientes sabem que um restaurante italiano por exemplo, em seu país, não será como os restaurantes que eles visitaram enquanto estavam na Itália. Assim, eles podem diminuir sua expectativas de autenticidade ao visitar um restaurante temático.

Quando perguntado sobre a atenticidade do Mumbai para o cliente, ele alegou que "lembra a culinária da Índia, mas certamente não vai ser igual a comida indiana. A gente sabe que vai ter uma adaptação brasileira, mas mesmo assim me agrada muito a culinária de países tão diferentes do nosso". Portanto apesar do cliente não ter visitado a Índia e ser um cliente ingeênuo segundo Ebster e Guist (2004), ele tem consciência que pode existir adaptações, mas ele aceita muito bem, pois ainda é uma experiência diferente é "exótico, me lembra um pouquinho a Índia, então a gastronomia deve ser algo similar". (Masculino, 35 anos).

Para a proprietária do Mumbai, ela considera seu estabelecimento temático "porque ele é todo colorido, eu acho que você se sente em outro local, você tem outro sentimento aqui dentro, primeiro que tem rosa, alaranjado, vermelho, quem vai ouvir, as vezes pensa: "Meu Deus, esse lugar deve ser horrível, mas quando você entra, você consegue ver a harmonia do local." E o cliente declarou "A gente come com os olhos, então além da gastronomia indiana, o Mumbai também consegue ser bem agradável, bem bonito, colorido e me passa algo bem aconchegante, e eu acho que os indianos também tem a cultura de receber bem em seus restaurantes locais, portanto considero tematico sim". Portanto, observa-se que nos dois pontos de vistas, o restaurante é visto como temático pela decoração e por toda a atmosfera criada e o cliente ainda vai mais fundo citando o conforto e o bem-estar, comparando com o que espera nos restaurantes da própria Índia e acreditando que o Mumbai proporcione uma sensação parecida. 


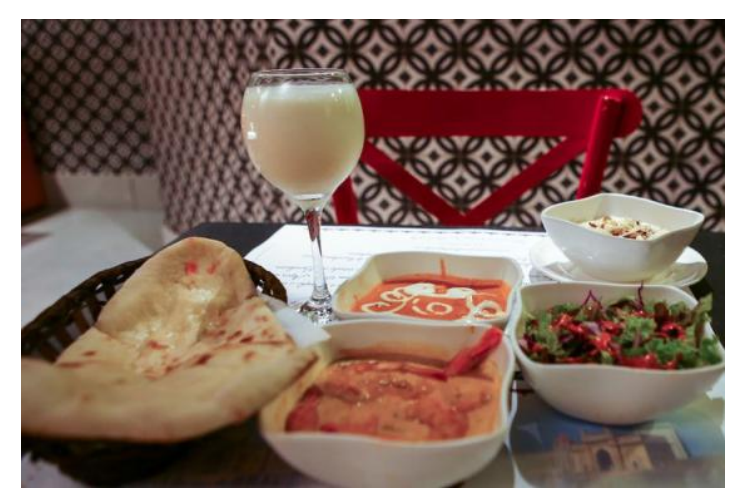

Fonte:www.metropoles.com

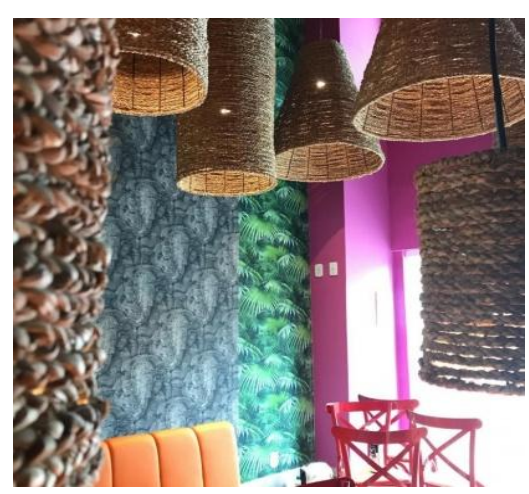

Fonte: gpslifetime.com.br

\section{Considerações Finais}

Os estabelecimentos gastronômicos temáticos merecem suas devidas análises, pois são espaços que apresentam realidades profundas, quando observadas atentamente. Espera-se que pelo menos em parte, o estudo tenha alcançado o objetivo de analisar o ponto de vista dos consumidores, proprietários e gerentes de estabelecimentos gastronômicos do Distrito Federal dentro de suas quatro divisões categóricas: temático relicário, temático paródico, temático reflexivo e temático étnico, além de também observar o "eatertainment" nesses espaços.

Foi notado que, a respeito dos temáticos relicários, seu conceito estará ligado à vontade de reviver algo, uma época, ou acontecimento do passado, transmitindo uma sensação nostálgica. A respeito dos paródicos, eles são os mais fantasiosos e os mais fáceis dos clientes detectarem que eles são temático, talvez, isto se dá pelo fato dos elementos temáticos não estarem apenas na decoração, mas também no cardápio, onde seus itens possuem nomes que remetem ao tema. Em relação ao reflexivo, ele parece ser o estabelecimento temático mais simples para ser coerente ao tema, uma vez que o próprio nome e elementos como cores e símbolos já remetem a uma marca específica.

E dentro dos temáticos étnicos, percebe-se a complexidade acerca da autenticidade em ambientes assim, pois eles são uma tentativa de recriar algo fora de seu contexto original. Mas, sabe-se que, um estabelecimento totalmente autêntico só existirá dentro de seu país de origem. O observado na pesquisa foi que, há elementos que aproximam os estabelecimentos da autenticidade e há elementos que distanciam os establecimentos da autenticidade. E, esses elementos podem estar juntos dentro de um mesmo estabelecimento. Portanto, talvez seja preciso aceitar suas contradições, pois o cliente tambem entende que é uma releitura e mesmo assim, recebe bem essa temática, pois o que busca é entrar em contato com uma gastronomia diferente e passar por uma experiência ímpar. 


\section{Referências Bibliográficas}

BEARDSWORTH, Alan e BRYMAN, Alan. Late modernity and the dynamics of quasification: the case of the themed restaurant. The Sociological. 1999.

EBSTER, Claus e GUIST, Irene. The Role of Authenticity in Ethnic Theme Restaurants. Journal of Food service Business Research. 2004.

GOTTDIENER, Mark. The theming of America: dreams,media fantasies, and themed environments. 2ed. Boulder: Westview Press. 1997.

SALES, Fabiana de Lima. Patrimônio cultural como insumo para atividade turística e recurso educacional no processo de educação patrimonial: o caso da educação patrimonial no Museu de Caxias do Sul. Dissertação de Mestrado. Caxias do Sul, UCS, 2006.

SILVA, Ernesto. História de Brasília. Senado Federal. 1985.

WOOD, Natalie T. e MUÑOZ, Caroline Lego. 'No rules, Just right' oris it? The roled of themed restaurants as cultural embassadors. Tourism and Hospitality Research. 2006. 